\title{
Fragen zum Thema „Akutes Abdomen“
}

\section{Welche Aussage zum Begriff „akutes Abdomen" trifft zu?}

A Es handelt sich um eine vorläufige, durch Zeitnot diktierte Arbeitsdiagnose für eine Gruppe von Erkrankungen, die mit Schmerzen, Bauchdeckenspannung und Schocksymptomatik einhergehen können.

B Der Begriff ist gleichbedeutend mit dem Begriff des „unklaren Abdomens“.

C Der Begriff beschreibt den üblichen postoperativen Verlauf nach operativen Eingriffen am Kolon.

D Der Begriff wird heute nicht mehr verwendet.

E Der Begriff beschreibt typischerweise periumbilikale Beschwerden.

\section{- 2. Ein 52-jähriger Patient liegt mit an-} gezogenen Beinen und bretthartem Abdomen blass und kaltschweißig auf der Untersuchungsliege. Was ist/sind Ihre erste(n) Maßnahme(n)?

A Sie erheben eine ausführliche Sozialanamnese.

B Sie punktieren das Abdomen.

C Sie erheben eine kurze, präzise Anamnese und führen sofort eine körperliche Untersuchung des Patienten durch.

D Sie veranlassen eine Computertomografie des Abdomens.

E Sie stellen den Versicherungsstatus fest.

\section{- 3. Mithilfe welcher Untersuchung lässt sich der Verdacht auf eine mesenteriale Ischämie am besten bestätigen?}

A Mit der Duplexsonografie

B Mit der Serumlaktatbestimmung

C Mit der CRP-Bestimmung.

D Mit der kontrastmittelverstärkten CT-Angiografie
E Mit einer Röntgenaufnahme des Abdomens

- 4. Welche Aussage trifft für die Pankreatitis als Ursache des akuten Abdomens zu?

A Sie wird immer operativ behandelt.

B Sie tritt nur in Kombination mit einer Cholezystolithiasis auf.

C Sie ist äußerst selten.

D Sie erfordert immer die Durchführung einer Computertomografie.

E Sie lässt sich durch die laborchemische Bestimmung der Serum-Lipase und/oder Amylase erkennen.

\section{- 5. Worauf weist ein Hb-Abfall im Aufnah- melabor bei einer jungen Frau mit akutem Abdomen am ehesten hin? \\ A Auf eine parasitäre Erkrankung \\ B Auf eine rupturierte Extrauteringravidität \\ C Auf eine Nephrolithiasis \\ D Auf einen Myokardinfarkt \\ E Auf eine inkarzierte Schenkelhernie}

-6. Welche Aussage zum perforierten Ulcus ventriculi/duodeni trifft zu?

A Es tritt nur bei jungen Männern auf.

B Es wird nicht operativ behandelt.

C Es kann kein bretthartes Abdomen verursachen.

D Es ist durch den Einsatz von Protonenpumpeninhibitoren in den letzten Jahren seltener geworden.

E Es führt typischerweise zu einem Unterbauchschmerz.

\section{Welche Aussage zur mesenterialen Ischämie trifft zu?}

A Sie wird in ihrer klinischen Bedeutung meist überschätzt.
B Sie ist mit einer Letalität von bis zu 70\% verbunden.

C Sie wird nur in der Spätphase der Erkrankung operativ behandelt.

D Sie besitzt eine eindeutige, leicht zu erkennende klinische Symptomatik.

E Sie kann durch die Bestimmung der Serum-Transaminasen erkannt werden.

- 8. Worin besteht eine sehr seltene Ursache des akuten Abdomens?

A Rupturiertes Viszeralarterienaneurysma

B Appendizitis

C Bridenileus

D Perforierte Sigmadivertikulitis

E Stenosierendes Kolonkarzinom

\section{- 9. Welches Vorgehen wird beim per-} akuten Abdomen empfohlen?

A Die sofortige Laparotomie als Notfalleingriff (z. B. bei massiver intraabdomineller Blutung)

B Eine abwartende Haltung ist der derzeitige Goldstandard.

C Es sollte zunächst eine Computertomografie durchgeführt werden.

D Es werden zunächst die Routinelaborparameter bestimmt.

E Die Laparotomie ist abzulehnen.

- 10. Mit welcher Symptomatik gehen Erkrankungen parenchymatöser Organe typischerweise einher?

A Mit einem scharfen und schneidenden Schmerz

B Mit kolikartigen Beschwerden

C Mit dumpfen, unbestimmbaren Schmerzen

D Ohne jegliche Beschwerden

E Mit einem epigastrischen Druckschmerz
Hier können Sie CME-Punkte sammeln a) für die Pflichtfortbildung aller Vertragsärzte und b) für freiwillige Fortbildungszertifikate, die viele Landesärztekammern anbieten.

Die Multiple-Choice-Fragen beziehen sich auf den vorangegangenen Fortbildungsbeitrag. Die Antworten ergeben sich z.T. aus dem Text, z.T. beruhen sie auf medizinischem Basiswissen! Wenn Sie 70\% der Fragen richtig beantworten, erhalten Sie 2, bei 100\% 3 CME-Punkte. So kommen Sie zu Ihren Punkten: Teilnahme unter www.cme-punkt.de. Teilnahmeschluss: 13. Mai 2011
CME-Herausgeber- und Review-Board: Dr. H. J. K. Barwitz, Prof. Dr. A. Berghaus, Prof. Dr. Dr. h.c. Th. Brandt, Prof. Dr. W. G. Daniel, Prof. Dr. W. Eisenmenger, Prof. Dr. K. Friese, Prof. Dr. H.S. Füessl, Prof. Dr. B. Göke, Prof. Dr. R. Gradinger, Prof. Dr. H. Holzgreve, Prof. Dr. A. Imdahl, Prof. Dr. K.-W. Jauch, Prof. Dr. K. Krüger, Prof. Dr. H.-J. Möller, Prof. Dr. D. Reinhardt, Prof. Dr. Dr. h.c. Th. Ruzicka, Prof. Dr. Ch. Stief, U. Weigeldt. 